\section{"Fraqueza de nascença": sentidos e significados culturais de impressões maternas na saúde infantil no Nordeste brasileiro}

\author{
"Birth weakness": cultural meanings \\ of maternal impressions for infant \\ health in Northeast Brazil
}

Paola Gondim Calvasina 1

Marilyn K. Nations 2,3

Maria Salete Bessa Jorge 1

Helena Alves de Carvalho Sampaio 1

\footnotetext{
1 Universidade Estadual do Ceará, Fortaleza, Brasil.

2 Universidade de Fortaleza, Fortaleza, Brasil.

${ }^{3}$ Harvard Medical School. Harvard University Harvard, U.S.A.

Correspondência P. G. Calvasina Universidade Estadual do Ceará.

Rua Joaquim Nabuco 455 , apto. 403, Fortaleza, CE 60125-120, Brasil. paolacalvasina@yahoo.com.br
}

\begin{abstract}
Pregnancy encompasses socio-cultural, historical, and affective dimensions that process various meanings in women's bodies. Each society constructs popular concepts, practices, and explanatory models that differ from the biomedical model and aim to protect the mother and fetus and foster a healthy pregnancy. This qualitative study, based on interpretative anthropology, unveils the experiences of 27 poor women and their repercussions on the malnutrition of their infants, treated at a Childhood Malnutrition Treatment Center in Fortaleza, Northeast Brazil. From January to June 2004, ethnographic and narrative interviews were conducted on so-called "birth weakness", in addition to participant observation of outpatient, nursing, and home childcare. The mothers believed that their own physical and emotional suffering and precarious nutritional status were "imprinted" on the fetus, resulting in the child's malnutrition. While the ethno-etiology of "weakness" points to factors outside the body that involuntarily affect the pregnant mother, the medical view tended to incriminate the mother herself. It is necessary to understand the mothers' narratives, sympathize with their suffering, and spawn a closer approach between the popular and biomedical concepts.
\end{abstract}

Pregnancy; Child Malnutrition; Cultural Anthropology
Introdução

Devido à importância do vinculo mãe-feto para a sobrevivência do recém-nascido, não é surpreendente que cada cultura constrói crenças populares sobre a vulnerabilidade da gestante e do feto, cria costumes protetores, proibições comportamentais e impõe tabus simbólicos para tentar controlar as incertezas e os perigos que os ameaçam 1,2,3,4, inclusive no Brasil 5,6.

A gestação abrange dimensões biológicas, afetivas, morais, históricas, sócio-culturais e econômicas que processam no corpo das mulheres significados, construídos a partir da experiência de cada uma 7 .

Na prática clínica, baseado no modelo biomédico, o corpo humano é visto como uma máquina composta de peças distintas, sendo a doença o mau funcionamento dos mecanismos biológi$\cos 8,9$. Assim, o corpo e a mente são divididos em entidades distintas. Os clínicos gerais ocupam-se do tratamento do corpo, enquanto psiquiatras e psicólogos cuidam da cura da mente. Esse hiato ocasiona desvantagens para a compreensão dos estados emocionais na saúde ${ }^{8}$, inclusive na gestação.

A desnutrição energética protéica fetal/infantil, por exemplo, é compreendida pela biomedicina como uma síndrome carencial que reúne variadas manifestações clínicas, antropométricas e metabólicas, em função da intensidade e duração da deficiência alimentar, dos fatores pa- 
tológicos (sobretudo infecções agregadas) e fase do desenvolvimento biológico do ser humano. Os indicadores antropométricos diretos (peso/ idade, peso/altura, altura/idade, plicometria, por exemplo) descrevem a expressão clínica da fome, classificando-a, segundo o déficit, em aguda ou crônica e estágio leve, moderado ou grave. Tal classificação divorcia as condições históricas, sociais e afetivas de quem vivencia o problema. Novas abordagens holísticas vêm aprofundando a cultura de populações específicas frente à desnutrição infantil, reconhecendo-se todas as influências no seu desencadeamento 10.

A discordância de interpretações entre pacientes e médicos é um hiato relevante para a compreensão do processo saúde-doença na sua totalidade. Pessoas leigas constroem as próprias concepções e racionalidades acerca das doenças, baseadas nas suas experiências vividas e no contexto cultural. Tais interpretações subjetivas, os modelos explicativos populares da enfermidade (illness), são ainda diferentes dos modelos explicativos profissionais da doença (disease) 11 .

A confrontação dos modelos explicativos populares e profissionais, durante o atendimento individual ou coletivo, pode resultar em desentendimentos e conflitos desnecessários entre médicos e pacientes e resistências às intervenções bem-intencionadas 12,13.

O modelo explicativo popular acerca do vinculo mãe-feto encontrado em diversas culturas é denominado "impressão materna". De acordo com esse conceito, que surgiu no século XVIII em Londres 14, o comportamento da mãe (dieta, consumo de bebida, drogas ou tabaco), estado mental e emocional, atitude moral, agressões físicas, exposição ao meio ambiente etc. pode afetar diretamente a fisiologia da reprodução e causar danos à criança ao nascer. A gestante, ao sentir desejos por uma comida ou bruscas alterações emocionais, físicas e ambientais, pode "imprimir" marcas diretamente no feto. São explicações evocadas depois do nascimento, para dar sentido às mudanças físicas ou deformidades no recém-nascido 1,3 .

A concepção parte do pressuposto de que tudo na natureza está conectado. Os fenômenos emocionais (raiva, ódio, medo, inveja, dor, piedade etc.), nutricionais (desejos alimentares) e ambientais (a fase da lua, a posição dos planetas e a mudança das estações), entre outros, podem deixar sua marca no feto, que é mais fraco e está à mercê do comportamento materno 2. É preciso manter harmonia durante a gestação, evitando extremos e excessos.

O modelo das impressões maternas foi desvelado por Snow et al. 15,16 nos anos 70, entre gestantes americanas de descendência africana e mexicana que faziam pré-natal em clínicas públicas em Michigan, Estados Unidos. Das 31 gestantes entrevistadas, $77 \%$ acreditavam que o feto podia ser "marcado", desfigurado ou até morto; $38 \%$ pensavam que o desejo alimentar não satisfeito poderia "marcar" a criança permanentemente; $90 \%$ acreditavam que as gestantes deveriam mudar sua dieta. Apesar do rico repertório cultural de precauções na gravidez, o conceito de "impressões maternas" era desconhecido pela maioria dos obstetras entrevistados.

O modelo explicativo profissional também reconhece que há comunicação na vida intrauterina através do cordão umbilical, que nutre e transmite emoções percebidas pelo feto 17,18 . As atitudes e sentimentos da mãe são divididos intensamente. Essa comunicação intra-uterina influenciará uma interação mãe-bebê ao nascer 19 .

As racionalidades que as gestantes utilizam, entretanto, são diferentes das explicações biomédicas 1,3. As vicissitudes concretas da vida real das mulheres pobres não coincidem com as abstrações fisicalistas do mundo clínico médico.

Uma visão holística da gestação exige que o profissional compreenda as narrativas do adoecimento de seus pacientes, da vida em si, em que a enfermidade é a resposta subjetiva às suas experiências, da família e de todo o seu relacionamento 3,8,9,20,21. As interpretações subjetivas das gestantes são relevantes no nordeste brasileiro, onde mães e bebês exibem vulnerabilidades à fome, às doenças infecciosas e à morte 22,23,24 .

Este estudo desvela as narrativas de gestantes pobres sobre as impressões maternas em relação à desnutrição infantil. Mergulhamos no mundo dessas mulheres para melhor compreender sua visão da realidade 25 .

\section{Percurso metodológico}

Este estudo foi realizado de janeiro a junho de 2004, num centro de referência no tratamento de crianças com desnutrição em Fortaleza, Ceará (população de 2,5 milhões de habitantes), no Nordeste brasileiro. As crianças atendidas nesse centro de desnutrição provêm da periferia de Fortaleza e do interior do estado, sendo encaminhadas pelas unidades de saúde, hospitais e vizinhos. Na chegada, uma equipe multidisciplinar avalia o estado nutricional/clínico da criança. Dependendo da gravidade, esta é encaminhada ao ambulatório, internada no centro ou em um hospital público de referência.

Utilizamos a metodologia qualitativa, fundamentada na antropologia interpretativa 26 , a qual permite uma liberdade auto-reflexiva 27 . Procuramos transpor o enfoque biomédico da desnutri- 
ção, buscando valorizar as experiências das mães na gestação e a repercussão destas nos seus filhos.

Após aprovação pelo Comitê de Ética em Pesquisa da Universidade Estadual do Ceará, entrevistas etnográficas, abertas e aprofundadas, foram realizadas com 27 mães de crianças desnutridas (com idade entre 2-72 meses) selecionadas aleatoriamente durante o atendimento. Nomes fictícios foram adotados para preservar a identidade dessas informantes-chave.

Apesar de serem mães jovens (70,3\% entre 17-30 anos; $29,7 \%$ entre $31-48$ anos), a maioria (70,3\%) já tem mais de dois filhos. São casadas ou vivem com um companheiro fixo $81,5 \%$, entretanto, $50 \%$ confessam que sofrem de violência doméstica dos parceiros, $9 \%$ desempregados. São separadas ou mães solteiras 18,6\%. Oitenta e cinco vírgula dois por cento são donas-de-casa sem renda ou desempregadas; três $(11,1 \%)$ dessas pedem esmolas na rua para "dá de comer" para seus filhos. Somente $14,8 \%$ trabalham em ocupações (domésticas, costureiras, lavadeiras etc.) que desgastam fisicamente e remuneram pouco; $100 \%$ ganham < 1 salário mínimo, sem carteira assinada. Sessenta e seis vírgula sete por cento das informantes têm, em média, cinco anos de estudo; 14,9\% são analfabetas.

Foram utilizadas questões norteadoras para revelar os significados culturais atribuídos às impressões maternas, desnutrição e saúde infantil. A narrativa da enfermidade 11,28,29,30 foi utilizada para que a mãe pudesse expressar livremente suas experiências durante a gestação e desenvolvimento do seu bebê. A observação-participante, com o seu vínculo de empatia, aproximou das mães e de sua realidade os pesquisadores, enriquecendo e validando os dados etnográficos 31 . Observações de cuidados e outras práticas relevantes foram anotadas num diário de campo, durante todo o percurso das mães no centro de desnutrição e em três domicílios visitados em Fortaleza.

Os dados qualitativos foram transcritos, relidos e organizados em um editor de texto. Após a leitura exaustiva e interrogativa, foram organizadas as categorias empíricas, a partir das unidades de significado emergentes 30,32 . Os dados foram interpretados sob o pano de fundo teórico da Antropologia Médica, Saúde Coletiva e Educação em Saúde.

\section{Resultados}

Fraqueza de nascença nas palavras e gestos das mães

No imaginário popular, são três as etnoetiologias da fraqueza de nascença: a herança biológica da carência nutricional da mãe, a “impressão” direta de acontecimentos, desejos e sofrimentos experienciados pela gestante no feto, e a combinação dessas duas formas na mesma gestação.

A primeira causa da fraqueza de nascença implica a falta de comida e desnutrição crônica sofrida pela mãe durante sua infância e adolescência que enfraqueceram seu corpo e, ao engravidar, essa herança biológica (fraqueza) é "passada" para o feto. Socorro, de 32 anos, nível médio completo, residente em um bairro pobre na periferia de Fortaleza, acredita que sua fraqueza passou para o filho de três anos com desnutrição leve. Em conseqüência das dificuldades na sua infância, ela cresceu marcada pela fome crônica e, mais tarde na vida adulta, passou sua fraqueza para o seu "bebê ainda na barriga".

"O bichinho nasceu fraco pelo que eu passei, né? (...) As dificuldades na minha família. Meu pai nunca tinha condição de dar a alimentação da gente. Eu ia pro colégio às vezes sem me alimentar porque realmente a gente não tinha trabalho. (...) A mãe ter passado coisas na infância, isso acontece com os filhos da gente também. (...) Quando uma criança não se alimenta bem (...) ela já cresce com aquela deficiência" (Socorro, 32 anos).

A segunda etnoetiologia do corpo fraco de nascença aponta uma grande variedade de fenômenos fisiológicos, químicos e emocionais. Tudo o que a mãe vivenciou durante a gestação influencia o desenvolvimento do filho. Tanto forças internas como externas podem agredir o corpo da mãe e, conseqüentemente, ser impressas ou tatuadas diretamente no feto, que nasce pouquinho (baixo peso ao nascer), magrelo e com choro fraquinho. As mães relatam que as "impressões" provocam também nascimentos prematuros, alergias, distúrbios alimentares, agressividade e hiperatividade nos filhos.

De acordo com as mães, desejos alimentares não satisfeitos, fome/"fastio" (falta de apetite), vícios químicos, emoções exageradas (preocupações, medo, raiva, ódio) causam a fraqueza. A gestante pode sentir o desejo de ingerir sua comida predileta (arroz cru, gelo, barro vermelho, areia) como se fosse um "pedido" do bebê na barriga. Caso contrário, o bebê pode nascer com a boca aberta (como se estivesse chorando pela comida negada), com uma mancha similar à comida desejada estampada no corpo ou ainda morto em razão do desejo não satisfeito. A mãe cuidadosa jamais ignora um "pedido" do filho, como Sandra, 23 anos, casada, com quatro filhos, nos contou. Embora sua médica tenha prescrito "umas vitamina" (sulfato ferroso) para fortificála e a tenha proibido de comer arroz cru, Sandra não resistiu ao "desejo medonho" de comê-lo. 
Foi impressa na pele do recém-nascido, então, uma massinha branca. Seu filho, Carlinhos, aos cinco anos, desenvolveu alergia a pão, macarrão e bolachas, alimentos baratos e básicos na dieta nordestina, contribuindo para o quadro de desnutrição moderada: "O médico disse que eu tinha um vício de comer arroz cru porque fazia mal e aquela massinha ficava na cabecinha e no corpinho dele. (...) Aí, me proibiram de comer arroz cru. Passou umas vitamina (...) sulfato ferroso, aí foi que eu fiquei boa. (...) A fraqueza dele, foi o que eu comi (...) passou para ele. Dra. Mônica fez dois exames, aí disse que ele não pode comer massa (...) pão, macarrão, bolacha" (Sandra, 23 anos).

Outra causa da fraqueza de nascença é a fome. Tânia, 30 anos, empregada doméstica, perdeu seu emprego durante a gravidez e ficou sem ter o que de comer. A fome (além das brigas, raiva e "pancadas" sofridas durante a gestação) deixaram impressões de nervosismo no filho de três anos. Tânia afirma que a desnutrição dele é "devido à raiva de tudo que eu passei": "Durante a gravidez, eu passei muita fome (...) de não ter ninguém pra fazer comida para mim. Ia dormir com o pai dele (...) depois fiquei grávida. Aí, aquela confusão de família. Minha irmã saiu de casa (...) levou tudo que eu tinha! Como é que eu ia viver, grávida sem mal me levantar? Era muita briga, muita confusão, muita raiva. Levei pancada (...) qualquer coisa ele quer bater. A desnutrição dele é devido 'a raiva de tudo que eu passei" (Tânia, 30 anos).

Ainda quando há comida suficiente em casa, a mãe pode não conseguir comer em decorrência do fastio (falta de apetite). Clara, 38 anos, pobre, com dois filhos desnutridos, sentiu um "ódio tão grande, uma vontade de matar, de chorar" durante a gravidez que a comida não entrava. Nem a insistência da mãe a fez comer. Só "chegar perto de comida de panela e enguiava". O sofrimento provocado ao ver calada seu marido lhe trair a deixou injuriada. A humilhação ("fazer pouco de mim") e o mau trato sofridos feriram seu corpo e alma. Clara não conseguiu engolir a traição, muito menos a comida.

"Eu sentia muita raiva na gravidez. (...) A minha mãe brigava muito: 'Clara tu se alimenta que tu vai ter neném! Os bichinho vão nascer fraquinho. Vão nascer desnutrido!' Mas a comida não entrava com um ódio tão grande, uma vontade de matar, de chorar. Eu não comia de jeito nenhum! Era só leite, pão, iorgute, bananada. Mas, comida de panela, não podia nem chegar perto que eu enguiava. (...) Grávida ele batia em mim porque não queria que eu me metia na frescura dele, né? Era pra eu ficar calada vendo ele curtindo e bebendo com a rapariga, fazendo pouco de mim no quintal, né? Ele chegava todo dia de manhã, liso, liso sem um tostão no bolso. Eu dizia: 'Cadê o dinheiro pra comprar o pão dos menino?' 'Não tenho um tostão, não!' E, eu ficava injuriada (...) quebrava as coisas. Então, foi por isso, o maltrato, maltrato que meu 'fi' foram desnutrido" (Clara, 38 anos).

As agressões químicas e fisiológicas provocadas pelo consumo de substâncias tóxicas pela mãe durante o desenvolvimento do feto podem também causar a fraqueza de nascença. As mães relatam que fumar cigarro, mascar fumo e ingerir bebida alcoólica durante a gravidez pode prejudica o feto. Lia, 21 anos, desempregada e mãe solteira de um filho de três anos com desnutrição moderada, deixa claro que o ato de fumar e beber (além da violência doméstica) "atingiu" o seu bebê, nascido prematuro de oito meses, roxo, sem chorar e cansado (dificuldade de respirar).

"Ele foi prematuro de oito meses. Foi parto cesariano (...) nasceu roxo, sem chorar, com cansaço. Foi direto para a incubadora e ficou dois meses na incubadora por causa que eu fumava muito cigarro, brigava muito com o pai dele. O pai dele me batia e atingiu ele. Aí, o médico perguntou (...) e eu não menti para ele, não! Disse que eu fumava cigarro, bebia grávida dele. Meu marido me batia (...) bateu até interar sete meses (...) deu um chute!"(Lia, 21 anos).

Sofrer emoções intensas como a raiva, ódio e revolta durante a gravidez, causam fraqueza, como já ilustrado no caso de Clara e outras. Raquel, 27 anos, dona-de-casa, também acredita que os traumas emocionais (o abandono, a solidão e a sobrecarga de trabalho) sofridos durante a gravidez afetaram sua filha, internada com desnutrição moderada.

"O meu emocional foi muito difícil porque dois meses depois que eu fiquei grávida, o pai dela foi embora. Eu sozinha lá, não tinha família. (...) O fato de eu ter ficado revoltada com ele, de eu não ter ninguém que me ajudasse, de tomar todas as providências sozinha (...) de registro tudo (...) tudo tinha que ser eu mesma, eu acredito que tenha passado para ela alguma coisa" (Raquel, 27 anos).

O impacto das emoções na gênese da fraqueza de nascença é enfatizado por Débora, 32 anos, moradora de um bairro pobre e perigoso na periferia de Fortaleza. Para ela, o pouco peso do seu filho de quatro anos foi causado pelo pavor e tormento que sentiu de assaltantes que ameaçavam estuprar grávidas, e dos tiroteios entre bandidos e policiais. O medo da violência afastou Débora das consultas pré-natais, resultando na fraqueza do filho.

"Tive muito medo. No bairro que eu moro tem muito ladrão e assaltante. (...) Lá quando os bandidos fazem assalto nas farmácias, corre tudo pra onde eu moro. Para esconder lá. Os policiais vêm atrás e começa a atirar! (...) A gente corre por cau- 
sa dos tiros ou fica trancada dentro de casa. (...) Tinha homem que entrava nas portas e dizia que ia estuprar as mulheres grávidas. (...) Eu morria de medo! Cheguei a sentir meu coração bater forte, quando escutava os tiros. Eu ficava só, trancava as portas e ficava toda enrolada numa rede com medo (...) atormentada, né?" (Débora, 32 anos).

Embora tenhamos isolado os fatores etiológicos para melhor compreendê-los, percebemos nas narrativas que a fraqueza é multifatorial, uma complexidade de forças que agridem o corpo, mente e alma de cada gestante e enfraquece o seu bebê. Na visão popular, as etiologias vão desde os desejos alimentares, o vício da nicotina, as relações conflituosas (brigas, traição, abandono), a violência física (pancadas, porradas, chutes, espancamentos) até as mudanças radicais no ambiente (despejo de casa, perda de pertences), entre outras. Enfim, a fraqueza de nascença reflete a totalidade do sofrimento vivido por essas mulheres durante a gestação, uma "desnutrição da alma”, que é estampada nos filhos, como explica Débora (32 anos): "Já fui muito atormentada! O bichinho já sofreu muito na minha barriga. Já veio para esse mundo sofrendo!".

\section{A biomedicina e a legitimação da racionalidade popular}

O discurso cientifico do médico, interpretado e relatado pelas informantes, reforça e legitima a racionalidade popular da fraqueza de nascença narrada por Socorro, Clara, Débora e outras. Embora as causas da desnutrição e do atraso no desenvolvimento do feto apontadas pela Biomedicina sejam similares aos da fraqueza de nascença, os médicos enfatizaram o perigo das mães passarem tudo para o bebê, ou seja, delas transmitirem algo prejudicial ao feto.

Durante o pré-natal o obstetra de Raquel, 27 anos, alertou que tanto substâncias (comidas, bebidas e cigarro) como as emoções podem ser transmitidas para o feto durante a gestação, contribuindo para a desnutrição da sua filha de um ano.

"O médico disse tudo passa para ele. Cientificamente os médicos falam que quando a gente tá grávida, tudo o que a gente come passa esse tipo de preferência para a criança. Se você fuma ou bebe isso afeta no desenvolvimento da criança, na estrutura óssea, neurologicamente. O fato do emocional também contribui. A criança pode nascer com alguma doença por causa do emocional, o amor que a gente dá ou não à criança também contribui" (Raquel, 27 anos).

Similarmente, Diana, 28 anos, relata que o pediatra alertou sobre a transmissão, para seu filho, das dificuldades experienciadas por ela durante a gestação (violência doméstica, dormir na rua, fome, noites mal dormidas, preocupações), resultando na hiperatividade ("danação") do seu filho de cinco anos. Os fatores de risco supostamente citados pelo médico relembram as explicações populares da fraqueza da nascença.

“Todo essa danação dele, foi bem esse negócio que eu passei. A gravidez dele muito sofrida. Apanhei do meu ex-esposo, fugi de casa, cheguei a dormir na rua, passei chuva, passei muita fome na gravidez dele. Eu sofri muito. Eu ia ter o menino praticamente na rua. Passei noites sem dormir, preocupação. Acho que tem a ver com a fraqueza dele muito. A médica disse que tudo que eu passei tem a ver com ele" (Diana, 28 anos; grifo nosso).

Durante o pré-natal, Sandra, 23 anos, relatou que seu obstetra suspeitou da morte intrauterina de seu filho, fato descartado após uma ultra-sonografia. De acordo com ela, o médico mencionou que o seu nervosismo produziu complicações na gravidez. Essa etiologia psíquica nos remete às explicações populares sobre o impacto das "emoções fortes" (ódio, raiva e revolta) na fraqueza de nascença: "Eu acho que afetou que eu fiquei com umas dorzinha na barriga. No outro dia eu fui para o médico. Aí, o médico disse que é porque eu fiquei muito nervosa. Era brigando com o meu marido. Ele saía, ia para a mãe dele. Eu ficava com raiva guardando aquela mágoa dentro de mim, aí coisava ele" (grifo nosso).

Apesar das concordâncias entre os modelos explicativos popular e profissional, percebemos uma sutil, embora crítica, diferença. Enquanto o modelo popular externa a gênese da fraque$z a$ em algo que é impresso no feto, ou seja, algo que involuntariamente atingiu o corpo da mãe, o modelo profissional aponta a própria mãe como responsável (e potencialmente culpada) por ter passado tudo para o seu filho.

A atitude equivocada dos obstetras de atribuir culpa às gestantes, talvez nos ajude a compreender as broncas que os médicos dão nas mães, durante as consultas, punindo-as simbolicamente pela “não-adesão” às prescrições clínicas.

Consideremos o caso de Débora, já discutido. O medo dos assaltantes e do estuprador de grávidas impediu-a de sair de casa, de fazer seu pré-natal e de tomar aquelas injeções. Para ela, o risco de ser baleada ou estuprada era maior do que ter uma gravidez descontrolada. Ao invés de compreender os sofrimentos vividos por Débora, a médica a castigou: "Eu não tive acompanhamento do pré-natal direito porque era a minha primeira gravidez. (...) Eu tinha muito medo de ir pro médico, de ver sangue, aquela coisa. Eu faltava às consultas. (...) Mas, só que ninguém me dava força pra ir, me incentivava. Só me dava medo. Aí, eu não ia. Quando eu tava com sete meses e oito foi que eu voltei a ir. A médica me deu a maior 
bronca, né? Disse que a minha gravidez tava toda descontrolada, que eu não tinha tomado as vacinas completa, que eu não tinha me alimentado. Nem uma vitamina eu tinha tomado, né! (...) Aî quando foram passar, eu já tava com nove meses. É por isso que ele ficou nessa, de pouco peso" (Débora, 32 anos; grifo nosso).

Causa, acusação e culpa

Embora a etnoetiologia da fraqueza de nascença envolva fatores que são involuntariamente "impressos", as mães entrevistadas se culpam por terem passado tudo para o bebê na barriga. Suas falas e gestos reproduzem o discurso culpabilizador dos médicos.

A racionalidade popular das "impressões maternas" e, subseqüentemente, a fraqueza de nascença localiza a origem não nos comportamentos individuais da mãe, mas nos fatores que atingem involuntariamente a mulher: nos desejos alimentares, na fome, na dependência química de álcool e nicotina, nas emoções intensas e nos desejos incontroláveis, e na violência física.

Nas narrativas percebemos, todavia, que as mães freqüentemente levantam a possibilidade de que seu comportamento tenha contribuído para a fraqueza do seu bebê. Rejane, 31 anos, desempregada, chega a questionar sua capacidade de cuidar da filha de um ano, com desnutrição moderada. "Às vezes eu me sinto mal como se eu não soubesse cuidar dela, sabe?” Já Roberta, 37 anos, assume a culpa pela desnutrição leve do filho de seis anos, mas depois responsabiliza a falta de vitaminas e não "alguma coisa de mim" pela desnutrição: "Eu acho que eu fui culpada. (...) Eu fico, assim, pensando: o que foi que eu fiz? Se eu tomei coisa que eu não era para tomar? Mas, eu nunca tomei nada na gravidez dos meus filhos. Eu tô grávida e pronto! Aí, eu sei que não foi alguma coisa de mim. Eu ficava só aquela barriguinha. Não sentia vontade de comer. Se eu tivesse tomado muita vitamina, eles não tinham nascido assim..." (Roberta, 37 anos; grifo nosso).

Essas mães, como muitas das nossas informantes, se punem porque acreditam que, de alguma forma, tenham prejudicado o filho em razão dos sofrimentos vividos na gestação. $\mathrm{Na}$ realidade, percebemos que as causas da fraqueza são fatores estruturais "impressos" na vida das mulheres nordestinas, forças sobre as quais elas possuem pouco poder para transformar.

\section{Discussão}

Este estudo acrescenta o conhecimento sobre a etnoenfermidade fraqueza de nascença, antes desconhecido pela biomedicina. A riqueza desse modelo explicativo popular avança, de forma incipiente, no entendimento da desnutrição sob uma visão holística.

Desde os anos 20, antropólogos-médicos vêm demonstrando que desvelar as etnoenfermidades ou culture-bound syndromes consiste em chave conceitual importante para compreender tanto a experiência subjetiva de adoecer quanto as doenças biomédicas relacionadas em países desenvolvidos 33,34,35,36,37 e em desenvolvimento 38,39,40,41,42, inclusive no Brasil 7,12,43,44,45.

Concordamos com Nations e Rebhun 24, que a fraqueza de nascença está relacionada com a desnutrição, uma doença de alta prevalência 46 e fatalidade infantil 47 no Nordeste brasileiro. Dessa forma, o corpo fraco simboliza a constituição física da criança e o seu status nutricional, portanto, a criança pode nascer fraca ou se tornar fraca 48 .

O modelo popular das impressões maternas, aqui demonstrado, revela que comportamentos (desejos alimentares, vícios químicos) e sofrimentos maternos (emoções fortes, violência emocional e física) podem afetar a fisiologia da reprodução e causar dano à criança após o nascimento. É semelhante aos dados relatados em outras culturas; Snow \& Johnson 15, Snow et al. 16 e Helman 3 , inclusive no Sul do Brasil 5,7 e no Ceará 49. Embora esses estudos corroborem com a existência de uma racionalidade leiga transcultural sobre o elo mãe-feto e os multi determinantes da saúde-doença infantil, não associam a impressão materna à desnutrição, como sugerido nesta pesquisa. Apontamos diferenças culturais no detalhamento etnográfico sobre as crenças e comportamentos no Nordeste brasileiro.

Enquanto no modelo explicativo popular da fraqueza de nascença é dito que a fome do bebê "é herdada da mãe", as carências (desejos) alimentares são tatuadas no feto, o "fastio" da mãe angustiada é impresso no filho, ocasionando a fraqueza no bebê, essa associação é relativamente recente, mais generalizada e menos detalhada no modelo profissional.

Nas ultimas décadas, a biomedicina evidenciou que a restrição de nutrientes durante a gestação pode afetar o desenvolvimento e crescimento fetal. Estudos médicos indicam que a mãe desnutrida pode gerar um bebê com baixo peso ao nascer 50 , com deficiências nutricionais (ácido fólico, vitamina B6, vitamina $\mathrm{C}$, vitamina A, vitamina $D$, vitamina $E$, vitamina $K$, cálcio, fósforo, zinco e ferro), retardo mental e do crescimento intra-uterino, hipocalcemia, hipoplasia de esmalte e anemia 51. A depleção de nutrientes no feto pode acarretar doenças na vida adulta, como hipertensão, doenças coronárias, diabetes 
tipo 2 51,52,53. O baixo peso ao nascer também pode ocorrer em virtude do alcoolismo e do tabagismo materno 54,55 .

A biomedicina também reconhece que, embora o sistema nervoso central da mãe e do feto sejam independentes, o estado emocional da gestante pode influenciar indiretamente sobre o estado de saúde do bebê. Emoções como ira, medo e ansiedade põem ativo o sistema nervoso autônomo da mãe, liberando certas substâncias químicas (como acetilcolina e epinefrina) na corrente sangüínea. Nessas condições, as glândulas endócrinas, particularmente as adrenais, secretam diferentes espécies e quantidades de hormônios. À medida que a composição do sangue se modifica, novas substâncias químicas são transmitidas através da placenta, produzindo alterações no sistema circulatório do feto ${ }^{18}$. Além disso, bebês de mães deprimidas e infelizes têm maior probabilidade de nascerem prematuros ou de apresentarem baixo peso ao nascer, de serem hiperativos, irritáveis, e ainda de manifestar dificuldades, tais como alimentação irregular, evacuação excessiva, gases, distúrbios no sono, choro excessivo e necessidades incomuns de ficar no colo 17,18.

No Brasil, estudos constataram que há influência emocional entre mães e filhos. As gestantes entrevistadas demonstravam preocupação com o nervosismo exacerbado nesse período, pois temiam algum prejuízo para o bebê 7 . Em Fortaleza, Antunes 49 , estudando as concepções populares na gestação e a evolução da linguagem infantil, identificou a importância do vínculo mãe-feto. É necessário que a gestante seja afetuosa com o bebê, "falando com a barriga", acariciando-a, alisando-a. A sabedoria popular também adverte que sentir emoções "negativas" - como o medo, insegurança, nervosismo ou raiva no decorrer da gravidez - pode "prejudicar" o feto, "custando a evoluir".

Neste estudo, não evidenciamos sinais de desligamento emocional entre mãe-feto ou negligência materna, no caso da fraqueza de nascença, como Scheper-Hughes 22,23 evidenciou. Descordamos da autora ao concluir que " $a$ fraqueza constitucional envolva uma falta de investimento materno" 23 (p. 302), pois gera bebês que não choram, não chamando atenção das mães, que negligenciam seus cuidados e os deixam morrer "à mingua".

Ao contrário, o modelo popular de impressões maternas enfatiza uma ligação profunda entre a gestante e o feto. As narrativas revelam mães atentas e preocupadas com as possíveis influências insalubres na gestação que poderiam prejudicar o bebê. As mães não acreditam que a fraqueza decorra do descuido, como postula
Scheper-Hughes 22,23, mas dos sofrimentos da vida: fome, "fastio", angústias emocionais, violência doméstica, falta de acesso às consultas pré-natais etc.

Nations \& Rebhun 24 reforçam nossos achados ao assinalarem que, se existe uma "negligência” no Nordeste brasileiro, não é por parte das mães pobres, mas de um sistema sócio-político e econômico injusto, que não cuida adequadamente dessas mulheres e de seus filhos. As autoras argumentam que os comportamentos maternos nesse contexto são mediados por construções culturais, que devem ser aprofundadas e compreendidas antes da interpretação dos motivos e ações no cuidado infantil. Hadad et al. 48 e Goulart et al. 56 também criticam interpretações que culpabilizam a mãe pelo óbito infantil em Minas Gerais, Brasil. A exclusão do acesso aos serviços públicos, problemas de comunicação e descontinuidade de cuidados, entre outros fatores, e não uma atitude materna descuidadora, foram identificados como responsáveis pela morte da criança.

Finalmente, os resultados provocam uma reflexão teórica sobre a comunicação clínica culpabilizadora. Embora as etnoetiologias de fraqueza de nascença, no Nordeste brasileiro, priorizem o elo mãe-feto na sua gênese, jamais implica ou responsabiliza a gestante como a causadora da doença. Na concepção popular, são forças e experiências na vida cotidiana que "infligem", "afetam”, “atingem”, “coisam”, "marcam”, "passam” e "imprimem” no corpo frágil do feto, independente da vontade da mãe. Ela acaba sendo a receptora passiva de influências danosas, sob as quais tem pouco (ou nenhum) poder para modificar. As explicações leigas, enfim, poupam e protegem a mãe pobre, já tão sofrida, do ônus da culpa.

Por outro lado, o discurso do médico-obstetra segundo o qual tudo passa para o bebê na gravidez, mesmo desconhecendo o modelo explicativo popular, é prontamente entendido pelas gestantes, pois a mensagem valida sua interpretação leiga das "impressões maternas”. Existe, porém, uma sutil diferença: a fala e os gestos dos profissionais transferem a responsabilidade (e a culpa) para o pensar e agir da mãe, como se ela agisse conscientemente. A sua criança nasceu com baixo peso, desnutrida e doente porque ela não se alimentou com uma dieta balanceada, não parou de fumar, não fez todos os exames pedidos, não tomou as vitaminas prescritas, não fez todas as visitas pré-natais etc.

Com a legitimação do médico, a mãe pode internalizar a culpa pela desnutrição do filho como vislumbramos no presente ensaio. Em vez de motivá-la a cuidar o melhor possível do seu bebê 
em um contexto de extrema pobreza, injustiça e desigualdades sociais, o discurso médico as castiga e deprime. Ryan 57 (p. 25) nos adverte sobre o processo insidioso da culpabilização de pessoas já fragilizadas por aquelas que as dominam: autoridades, profissionais e elites: "Típica (da postura de culpar a vítima) é desviando do alvo central que requer uma mudança sistemática e, em vez disso, focalizar no indivíduo afetado. O último efeito é sempre distrair atenção da causa básica, deixando de fora as injustiças sociais primárias. $E$, mais reveladora, a proposta para remediar o problema é, claro, trabalhar na própria vítima: mudar suas atitudes, alterar seus valores (...) curar seus defeitos de caráter (...) nunca mudar as circunstâncias em volta".

Para Kleinman 11 , Caprara \& Franco ${ }^{58}$, Nations \& Nuto 13 e Caprara \& Rodrigues 59 , a diversidade cultural na comunicação médico-paciente é uma realidade que os médicos precisam gerenciar em sua prática clínica. Exige que eles sejam capazes de aprender novos valores e desenvolver outras percepções de saúde-doença. Trata-se de uma aprendizagem indispensável para uma medicina humanizada.

\section{Resumo}

A gestação abrange dimensões sócio-culturais, históricas e afetivas, que processam no corpo das mulheres diversos sentidos e significados. Cada sociedade constrói concepções, práticas ou modelos explicativos populares, que se diferenciam do modelo biomédico e visam a proteger a mãe-feto, promovendo uma gravidez saudável. Esta pesquisa qualitativa, baseada na antropologia interpretativa, desvela as experiências vivenciadas por 27 mulheres pobres e suas repercussões na desnutrição dos filhos atendidos num Centro de Desnutrição Infantil em Fortaleza, Nordeste brasileiro. De janeiro a junho de 2004, foram realizadas entrevistas etnográficas e narrativas sobre fraqueza de nascença e observação-participante de cuidados no ambulatório, enfermaria e domicílios. Conforme se argumenta, as mães acreditam que seus sofrimentos físicos, emocionais e a precária condição nutricional é "impressa" no feto, resultando na desnutrição do filho. Enquanto a etnoetiologia da "fraqueza" aponta fatores externos do corpo que involuntariamente atingem a gestante, a visão médica relatada tende a culpabilizar a mãe. É preciso compreender a narrativa das mães, sensibilizar-se com o seu sofrimento e aproximar as concepções populares e biomédicas.

Gravidez; Desnutrição Infantil; Antropologia Cultural

\section{Considerações finais}

As mães nordestinas entrevistadas se esforçam para cuidar de seus filhos, apesar da pobreza e da miséria em que vivem. A questão do nascer fraco sinaliza as impressões de fome, "fastio", vícios e sofrimentos, que podem alterar sua nutrição durante a gestação e, conseqüentemente, a do feto.

As mães compreendem o adoecimento e a desnutrição dos seus filhos como um processo de todo o corpo, inerente às dificuldades físicas, sociais e emocionais que vivenciaram na gestação.

O estudo nos desperta para a dureza do sofrimento social no Nordeste brasileiro e das competências culturais da população para enfrentá-la. É preciso compreender as histórias de vida da gestante, para aproximar as concepções populares e biomédicas acerca da nutrição e saúde. A capacidade de decodificar a linguagem materna, eliminar barreiras de acesso aos serviços, desculpabilizar a gestante como a causadora da desnutrição infantil e, por fim, dignificar a mulher fragilizada pelo sofrimento social, parecem tarefas essenciais na formação do profissional de saúde humanizado.

\section{Colaboradores}

P. G. Calvasina coletou os dados e redigiu o artigo. M. K. Nations participou na organização do artigo, contribuiu na análise, metodologia e redação do texto. M. S. B. Jorge participou na construção da metodologia. H. A. C. Sampaio acompanhou a coleta dos dados, contribuiu na análise e redação do texto. 


\section{Referências}

1. Snow LF. Folk medical beliefs and their implications for care of patients. Ann Intern Med 1974 81:82-96

2. Snow LF. Popular medicine in a black neighborhood. In: Spicer EH, editor. Ethnic medicine in southwest. Tucson: The University of Arizona Press; 1977. p. 19-95.

3. Helman CG. Cultura, saúde e doença. Porto Alegre: Editora Artes Médicas; 2003.

4. Faundes A, Barzelatto J. O drama do aborto: em busca de um consenso. Campinas: Editora Komedi; 2004.

5. Leal OF. Sangue, fertilidade e práticas contraceptivas. In: Leal O, organizador. Corpos e significados: ensaios de antropologia social. Porto Alegre: Universidade Federal do Rio Grande do Sul; 1995.

6. Nations MK, Misago C, Fonseca W, Correia LL, Campbell OM. Women's hidden transcripts about abortion in Brazil. Soc Sci Med 1997; 44:1833-45.

7. Paim HHS. Marcas no corpo: gravidez e maternidade em grupos populares. In: Duarte LFD, Leal OF, organizadores. Doença, sofrimento perturbações: perspectivas etnográficas. Rio de Janeiro: Editora Fiocruz; 2001. p. 31-47.

8. Capra F. O ponto de mutação - a ciência, a sociedade e a cultura emergente. São Paulo: Cultrix; 1982.

9. Kleinman A. Writing at the margin: discourse between anthropology and medicine. Berkeley: University of California Press; 1995

10. Freitas MCS. Agonia da fome. Salvador: Editora da Universidade Federal da Bahia/Rio de Janeiro: Editora Fiocruz; 2003.

11. Kleinman A. Patients and healers in the context of culture: an explanatory of borderland anthropology and psychiatry. Berkeley: University of California Press; 1980.

12. Nations MK, Monte CM. "I'm not dog no": cries of resistance against cholera control campaigns. Soc Sci Med 1996; 43:1007-24.

13. Nations MK, Nuto SAS. Tooth worms, poverty tattoos and dental care conflicts in Northeast Brazil Soc Sci Med 2002; 54:229-44.

14. Bynum B. Maternal impression. Lancet 2002; 359:898.

15. Snow LF, Johnson SM. Modern day menstrual folklore. Some clinical implications. JAMA 1977 237:2736-9.

16. Snow LF, Johnson SM, Mayhew HE. The behavioral implications of some old wives tales. Obstet Gynecol 1978; 51:727-32.

17. Sameroff AJ, Zax M, Babigian HM. Birth outcomes in the offspring of mentally disordered womem. Am J Orthopsychiatry 1977; 47:218-30.

18. Mussen PH, Conger JJ, Kagan J, Huston AC. Desenvolvimento e personalidade da criança. São Paulo: Editora Harbra; 2001

19. Winnicott D. A criança e o seu mundo. Rio de Janeiro: Jorge Zahar Editor; 1982.

20. Eisenberg L. Disease and illness: distinctions between professional and popular ideas of sickness. Cult Med Psychiatry 1977; 1:9-23.
21. Uchôa E, Vidal JM. Antropologia médica: elementos conceituais e metodológicos para uma abordagem da saúde e da doença. Cad Saúde Pública 1994; 10:497-504.

22. Scheper-Hughes N. Culture, scarcity, and maternal thinking: maternal detachment and infant survival in a Brazilian Shantytown. Ethos 1985; 13:291-317.

23. Scheper-Hughes N. Death without weeping: violence in everyday life in Brazil. Berkeley: University of California Press; 1992.

24. Nations MK, Rebhun LA. Angels with wet wings won't fly: maternal sentiment in Brazil and the image of neglect. Cult Med Psychiatry 1988; 2: 141-200.

25. Berger PL, Luckmann T. The social construction of reality. A treatise in the sociology of knowledge. New York: Anchor Books; 1966.

26. Geertz C. A interpretação das culturas. Rio de Janeiro: LTC Editora; 1989.

27. Richards L, Morse JM. Read me first for a user's guide to qualitative methods. London: Sage Publications; 2002.

28. Rabelo MCM, Alves PCB, Souza IMA, organizadores. Experiência de doença e narrativa. Rio de Janeiro: Editora Fiocruz; 1999.

29. Lira GV, Catrib AMF, Nations MK. A narrativa na pesquisa social em saúde: perspectiva e método. Rev Bras Promoção Saúde 2003; 16:59-66.

30. Caprara A, Veras MS. Hermenêutica e narrativa: a experiência de mães de crianças com epidermólise bolhosa congênita. Interface Comun Saúde Educ 2004; 9:131-46.

31. Minayo MC. O desafio do conhecimento: pesquisa qualitativa em saúde. $7^{\text {a }}$ Ed. São Paulo: Editora Hucitec/Rio de Janeiro: ABRASCO; 2000.

32. Ekman I, Ehnfors M, Norberg A. The meaning of living with severe chronic heart failure as narrated by elderly people. Scand J Caring Sci 2000; 14:130-6.

33. van Loon FHG. Amok and lattah. J Abnorm Soc Psychol 1926; 21:434-44.

34. Rubel AJ. The epidemiology of a folk illness: susto, in hispanic America. Ethnology 1964; 3:268-83.

35. Foulks EF. The Artic hysterias of the North Alaskan eskimos. Washington DC: American Anthropological Association; 1972. (Anthropological Studies, 10).

36. Helman CG. "Feed a cold, starve a fever": folk models of infection in an English suburban community and their relation to medical treatment. Cult Med Psychiatry 1978; 2:107-38.

37. Nations MK, Camino LA, Walker FB. Hidden popular illnesses in primary health care: physician's recognition and clinical implications. Cult Med Psychiatry 1985; 9:223-40.

38. Harris G. Possession "hysteria" in a Kenya tribe. Am Anthropol 1957; 59:1046-66.

39. Hoskin JO, Kiloh IG, Cawte JE. Epilepsy and guria: the shaking syndromes of New Guinea. Soc Sci Med 1967; 3:38-48.

40. Good BJ. The heart of what's the matter: the semantics of illness in Iran. Cult Med Psychiatry 1977; 1:2-58. 
41. Guarnaccia P, Farias P. The social meanings of nervios: a case study of a Central American woman. Soc Sci Med 1988; 26:1223-31.

42. Philippe J, Romain JB. Indisposition in Haiti. Soc Sci Med [Med Anthropol] 1979; 13B:129-33.

43. Duarte LFD. Da vida nervosa: nas classes trabalhadoras urbanas. Rio de Janeiro: Jorge Zahar Editor; 1986.

44. Nations MK. The child's disease (doença de criança): popular paradigm of persistent diarrhea? Acta Paediatr 1992; 381:55-65.

45. Silveira ML. O nervo cala, o nervo fala: a linguagem da doença. Rio de Janeiro: Editora Fiocruz; 2000. (Coleção Antropologia e Saúde).

46. Bem-Estar Familiar no Brasil. Pesquisa nacional sobre demografia. Rio de Janeiro: Bem-Estar Familiar no Brasil; 1996.

47. Oliveira JC, Albuquerque FR. A mortalidade no Brasil no período 1980-2004: desafios e oportunidades para os próximos anos. Rio de Janeiro: Instituto Brasileiro de Geografia e Estatística; 2005.

48. Hadad SC, França E, Uchôa E. Preventable infant mortality and quality of health care: maternal perception of child's illness and treatment. Cad Saúde Pública 2002; 18:1519-27.

49. Antunes DK. A construção cultural da "evolução" da linguagem infantil: um repensar da prática fonoaudiológica [Dissertação de Mestrado]. Fortaleza: Universidade de Fortaleza; 2001.

50. Ramakrishnan U. Nutrition and low birth weight: from research to practice. Am J Clin Nutr 2004; $79: 17-21$.
51. Hamaoui E, Hamaoui M. Nutritional assessment and support during pregnancy. Gastroenterol Clin North Am 1998; 27:89-121.

52. Langley-Evans SC, Gardner DS, Welham SJ. Intrauterine programming of cardiovascular disease by maternal nutritional status. Nutrition 1998; 14: 39-47.

53. Godfrey K, Barker D. Fetal nutrition and adult disease. Am J Clin Nutr 2000; 71 Suppl:1344S-52S.

54. Wenman WM, Joffres MR, Tataryn IV. A prospective cohort study of pregnancy risk factors and birth outcomes in Aboriginal womem. Can Med Assoc J 2004; 171:577-97.

55. Leopércio W, Gigliotti, A. Tabagismo e suas peculiaridades durante a gestação: uma revisão crítica. J Bras Pneumol 2004; 30:176-85.

56. Goulart LMHF, Somarriba MG, Xavier CC. A perspectiva das mães sobre o óbito infantil: uma investigação além dos números. Cad Saúde Pública 2005; 21:715-23.

57. Ryan W. Blaming the victim. New York: Vintage 1971.

58. Caprara A, Franco AL. A relação paciente-médico: para uma humanização da prática médica. Cad Saúde Pública 1999; 15:647-54.

59. Caprara A, Rodrigues J. A relação assimétrica médico-paciente: repensando o vínculo terapêutico. Ciênc Saúde Coletiva 2004; 9:139-46.

Recebido em 10/Mai/2005

Versão final reapresentada em 25/Mai/2006

Aprovado em 12/Jun/2006 